\title{
20th century artists' oil paints: The case of the Olii by Lucio Fontana
}

\author{
Francesca Caterina Izzo ${ }^{\mathrm{a}, *}$, Barbara Ferriani ${ }^{\mathrm{b}, 1}$, Klaas Jan Van den Berg ${ }^{\mathrm{c}, 2}$, \\ Henk Van Keulen ${ }^{c, 2}$, Elisabetta Zendri ${ }^{\mathrm{a}, 3}$ \\ a Ca' Foscari University of Venice, Department of Environmental Sciences, Informatics and Statistics, Via Torino 155/b, 30174 Venezia Mestre, Italy \\ ${ }^{\mathrm{b}}$ Barbara Ferriani srl, Via Vettabbia 1, 20122 Milano, Italy \\ ${ }^{\mathrm{c}}$ RCE-Rijksdienst voor Cultureel Erfgoed/Netherlands Cultural Heritage Agency, Sector Kennis Roerend Erfgoed/Research Movable Heritage, P.O. Box 76709, \\ 1070 KA Amsterdam, Netherlands
}

\section{A R T I C L E I N F O}

\section{Article history:}

Received 13 June 2013

Accepted 3 November 2013

Available online $\mathrm{xxx}$

\section{Keywords:}

Lucio Fontana

Fine di Dio

20th century oils

Contemporary paintings

Manufactured artists' oils

GC-MS technique

Pictorial films

Restoration

\begin{abstract}
A B S T R A C T
During the 20th century, many innovative binders have been rapidly introduced to the art world and soon became popular as artists' paints and pictorial media. However, despite the advantages that new synthetic materials presented, oil paints have never been entirely substituted. Indeed, this paper focuses on the results provided by the scientific analysis of a group works from the oeuvre of Lucio Fontana (1899-1968), all of which created between 1960 and 1964 using oil-based media, and aims to illustrate how oils contained in the pictorial media have influenced these works' respective ageing and degradation processes. Despite the apparent coherence in the behaviour of many of Fontana's creations, some artworks revealed discrepancies in terms of the physical and mechanical behaviour of the pictorial films and in alterations resulting from degradation processes. Samples taken from case studies belonging to the Olii and Fine di Dio series were analysed using optical microscopy, X-Ray Fluorescence (XRF), FourierTransform Infrared Spectroscopy in attenuated total reflectance (FTIR-ATR) and Gas ChromatographyMass Spectrometry (GC-MS) in order to study and identify the materials employed by the artist and the products of their degradation processes. These analyses gave unexpected but useful results (such as the presence of non-drying or slow-drying oils in the paint formulations) which not only provided us with new insight into the nature of the constituent materials, but also facilitated the elaboration of correct conservation measures and suitable restoration interventions.
\end{abstract}

(c) 2013 Elsevier Masson SAS. All rights reserved.

\section{Introduction and aims of the research}

During the first decades of the 20th century, many innovative binders were introduced to the art world and soon became popular as artists' paints and painting media [1-3]. As a direct consequence, the composition and nature of many artistic and pictorial binders were thus subjected to radical changes. However, despite the advantages that these new synthetic materials presented, oils continued to dominate as the most versatile binding medium, and have never been entirely substituted $[4,5]$.

This research, part of a larger research project dedicated to the nature of 20th Century artists' oil paints (namely the 20th Century oil paints Project), deals with a group of works by one

\footnotetext{
* Corresponding author. Tel.: +39 041 2346730; fax: +39 0412346729.

E-mail addresses: fra.izzo@unive.it (F.C. Izzo), info@barbaraferrianisrl.com (B. Ferriani), k.van.den.berg@cultureelerfgoed.nl (K.J.V.d. Berg),

h.van.Keulen@cultureelerfgoed.nl (H. Van Keulen), elizen@unive.it (E. Zendri).

${ }^{1}$ Tel.: +3902583 28511; fax: +390258327774.

2 Tel.: +3120305 47 10; fax: + 31203054700 .

${ }^{3}$ Tel.: +39041 2346730; fax: +390412346729.
}

of the most important Italian artists of the 20th century, Lucio Fontana (1899-1968). Even though previous studies have shown that Fontana had started to use new synthetic binders as substitutes for traditional oils [6-9], this survey focused specifically on the analysis of works from the Olli and the Fine di Dio series created between 1960 and 1964, in which, the artist used the classical pictorial medium of oils with new expressive aims. In these series, Fontana usually applied monochromatic pictorial layers to the canvas, then, while the medium was drying, he pierced, engraved and manipulated the paint, which soaked into and around the edges of the holes and even leaked onto the rear of the canvas. The artist applied the oil media in a thick impasto using brushes, spatulas and his fingers in order to achieve a sculptural effect, and sometimes glued shaped elements such as small pieces of coloured glass or sequins onto the surface. The paint layers of the works belonging to these series are normally compact and rigid, and seldom present conservative problems. However, with time some of the pictorial surfaces have begun to show the effects of the drying process and the movement of the support (which generally manifest in the form of craquelures), but rarely actual losses in the paint layer or its detachment from the canvas have been noticed. Despite the apparent coherence in the behaviour of many of Fontana's 
Table 1

A short description of the analysed paintings by Lucio Fontana and the observations about their state of conservation before restoration.

\begin{tabular}{|c|c|c|}
\hline Paintings $^{\mathrm{a}}$ & Description & State of conservation \\
\hline $\begin{array}{l}\text { Concetto Spaziale. Notte d'amore a } \\
\text { Venezia, 1960, Fondazione Lucio } \\
\text { Fontana ( } 60081), 80 \times 100 \mathrm{~cm}\end{array}$ & $\begin{array}{l}\text { This rectangular canvas, belonging to the Concetto Spaziale (Olii) series, } \\
\text { is covered in monochromatic red-brown paint; the pictorial surface } \\
\text { presents punctures, cuts and scratched incisions }\end{array}$ & $\begin{array}{l}\text { The reddish-brown pictorial layer was } \\
\text { wrinkled and widespread craquelure } \\
\text { has created 'islands' which tend to } \\
\text { detach from the fabric support (Fig. 1a). } \\
\text { In some places, this phenomenon was } \\
\text { so advanced that it has caused losses in } \\
\text { the paint layer. In some parts, the paint } \\
\text { layer appears to be extremely brittle } \\
\text { and fragile, while in others, it is still } \\
\text { sticky and only partially dry }\end{array}$ \\
\hline
\end{tabular}

Concetto Spaziale, 1962, Fondazione Lucio Fontana (62 0 66), $145 \times 115 \mathrm{~cm}$

Concetto Spaziale, 1962, Fondazione Lucio Fontana (17 37/92), $100 \times 80.5 \mathrm{~cm}$

Concetto Spaziale. Fine di Dio, 1963, Fondazione Lucio Fontana (63 FD 14), $178 \times 123 \mathrm{~cm}$

Concetto Spaziale. Fine di Dio, 1963 , Fondazione Lucio Fontana (63 FD 23), $178 \times 123 \mathrm{~cm}$
This rectangular canvas, belonging to the Concetto Spaziale (Olii) series, is covered in monochromatic pink paint with slashes, cuts and graffiti

This rectangular canvas, belonging to the Concetto Spaziale series, is covered in monochromatic pink paint with slashes, cuts and graffiti

This oval painting, belonging to the Concetto Spaziale (Fine di Dio) series, is characterized by a monochromatic pink paint with punctures, cuts and scratched incisions

This monochromatic black oval work, belonging to the Concetto Spaziale (Fine di Dio) series, presents punctures, slashes and sequins glued to the surface
These three pink Concetto spaziale artworks presented all the same type of deterioration: strange, lighter yellow stains in the form of drops and puddles were noted on the painted surfaces (Fig. 1b)

In this black Concetto Spaziale, the edges of the slashes appeared to be deformed and instead of protruding onto the rear, they appeared to have contracted and had pushed through onto the front of the canvas (Fig. 1c)

It did not present any unusual alterations and therefore represented an ideal reference standard (Fig. 1d)
Concetto spaziale. Fine di Dio, 1964, Fondazione Lucio Fontana (64 FD 5), $178 \times 123 \mathrm{~cm}$
This monochromatic yellow painting on an oval canvas with punctures, slashes and scratches belongs to the Concetto Spaziale (Fine di Dio) series

a Fontana's works are classified in the general catalogue by year, the initial letter of the series and the number of the work within its respective series - hence 60 o 81 should be read as a work dated to 1960 , belonging to the Olii series and the 81 st work catalogued in this series, and so on for the other paintings analysed.

creations, some works belonging to the abovementioned series have revealed discrepancies in terms of both the physicalmechanical behaviour of the pictorial film and in terms of alterations resulting from degradation processes. A short description of the six works of art and the observations about their state of conservation before the restoration treatments are listed in Table 1. These anomalies could have been interpreted as the results of ageing, humidity, heat, radiation or previous restoration processes, but with the aim of better understanding their conservation conditions and ageing behavior, it was decided to investigate the possibility that these anomalies resulted from the nature of the paint composition itself.

\section{Experimental}

\subsection{Samples}

The opportunity of investigating the aforementioned artworks by Fontana was presented when these paintings required restoration, and samples were provided thanks to the generosity of the works' owners and the Fondazione Lucio Fontana in Milan, Italy. Micro-fragments of the respective pictorial layers were taken from the back sections or lateral margins of the paintings, some of which also contained the ground layer of the canvas. These samples were found to be composed of different layers of monochromatic paints and in some cases contained glass fragments or sequins, glued by the artist on the paint.

\subsection{Instrumental details}

Samples were observed both in visible and UV light with an Olympus SZX16 optical microscope equipped for microphotography.
XRF was carried out using a Bruker Tracer III-V portable XRF instrument, equipped with a low power Rh-tube operating at $40 \mathrm{kV}$ and $2.2 \mathrm{uA}$ and a peltier cooled Si-PIN detector.

FTIR-ATR was performed using a Perkin Elmer Spectrum 1000 FTIR combined with a Graseby Specac Golden Gate Single Reflection Diamond ATR, from 4000 to $600 \mathrm{~cm}^{-1}$ for 64 scans and a resolution of $4 \mathrm{~cm}^{-1}$.

GC-MS analysis was performed using a Thermo Quest GC-8000 instrument with a Supelco Column equity $5,30 \mathrm{~m}, 0.25 \mathrm{~mm}, 0.5$ um interfaced with MS MD-800. The inlet temperature was $300^{\circ} \mathrm{C}$, the MS interface was at $270^{\circ} \mathrm{C}$. The temperature program was set from $120^{\circ} \mathrm{C}$ to $300^{\circ} \mathrm{C}$ with a ramp of $10^{\circ} \mathrm{C} / \mathrm{min}, 3 \mathrm{~min}$. The MS was run in Full Scan mode (m/z 40-600), 1.9 scans/s. Solvent delay was set at $4.5 \mathrm{~min}$. The transfer line was at $240^{\circ} \mathrm{C}$ and the source temperature was $220^{\circ} \mathrm{C}$. Electron Ionisation energy was $70 \mathrm{eV}$. Samples were prepared using (trifluoromethylphenyl) trimethylammonium hydroxide, overnight reaction: fatty acids were transesterified into their correspondent methyl esters, while the glycerol reacted forming different (trifluoromethyl)phenyl ethers $[10,11]$.

\section{Results and discussion}

Table 2 fully reports the typology of the examined samples and the analytical results obtained by XRF, FTIR-ATR and GC-MS on the six Fontana's paintings.

The Concetto spaziale. Notte d'amore a Venezia (60 0 81) (detail shown in Fig. 1a) was analysed as both ground and pictorial layers. The white ground layer is composed of a mixture of linseed oil and lead white $\left(2 \mathrm{PbCO}_{3} \cdot \mathrm{Pb}(\mathrm{OH})_{2}\right)$, with zinc oxide $(\mathrm{ZnO})$, calcium carbonate $\left(\mathrm{CaCO}_{3}\right)$ and barium sulphate $\left(\mathrm{BaSO}_{4}\right)$ as whiteners and/or fillers. The presence of a lead soap was observed thanks to the FTIR absorption peak at around $1530 \mathrm{~cm}^{-1}$ : this was most likely due to the absorption of lead carboxylates formed as products after the reaction of the oil binder with the lead pigment 
Samples analysed and analytical results obtained by XRF, FTIR-ATR and GC-MS on the six Fontana's paintings.

\begin{tabular}{|c|c|c|c|c|c|}
\hline Paintings & Samples & XRF results & FTIR ATR results & GC-MS results ${ }^{\mathrm{a}}$ & Considerations \\
\hline \multirow[t]{2}{*}{ 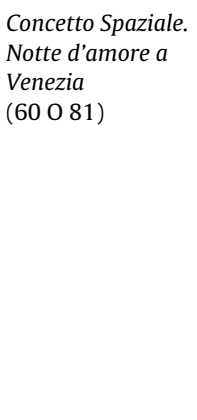 } & White ground layer & S, Ba. Ca, Zn, Pb & $\begin{array}{l}\text { Drying oil } \\
\text { Carbonates } \\
\text { Calcium sulphate } \\
\text { Lead carboxylates }\end{array}$ & $\begin{array}{l}\text { Saturated monocarboxylic (lauric, myristic, } \\
\text { palmitic, stearic) and dicarboxylic (suberic, } \\
\text { azelaic, sebacic) acids; unsaturated (oleic) } \\
\text { acids; glycerol } \\
\mathrm{P} / \mathrm{S}=1.4 \\
\mathrm{~A} / \mathrm{P}=5.6\end{array}$ & \multirow{2}{*}{$\begin{array}{l}\text { The ground layer is composed of a } \\
\text { mixture of linseed oil and lead white } \\
\left(2 \mathrm{PbCO}{ }_{3}{ }^{*} \mathrm{~Pb}(\mathrm{OH})_{2}\right) \text { with zinc oxide } \\
(\mathrm{ZnO}) \text {, calcium carbonate }\left(\mathrm{CaCO}_{3}\right) \text { and } \\
\text { barium sulphate }\left(\mathrm{BaSO}_{4}\right) \text { as } \\
\text { whiteners/fillers. It shows the presence } \\
\text { of lead soaps } \\
\text { The red-brown layer is composed of a } \\
\text { modified linseed oil paint with the } \\
\text { addition of ricinoleic acid, mixed with } \\
\text { alizarin }\end{array}$} \\
\hline & Red-brown paint & $\begin{array}{l}\text { Traces of S, Ba. Ca, } \\
\text { Zn } \\
\text { (probably } \\
\text { contamination } \\
\text { from the ground } \\
\text { layer) }\end{array}$ & $\begin{array}{l}\text { Oil-based paint } \\
\text { Organic red } \\
\text { dyestuff }(1,2- \\
\text { dihydroxyanthraquinone, } \\
\text { also known as } \\
\text { alizarin, Mordant } \\
\text { Red } 11 \text { or Turkey } \\
\text { Red) }\end{array}$ & $\begin{array}{l}\text { Alizarin } \\
\text { Saturated monocarboxylic (palmitic, stearic, } \\
\text { arachidic, behenic) and dicarboxylic (suberic, } \\
\text { azelaic, sebacic) acids; unsaturated (oleic, } \\
\text { linoleic) acids; glycerol; ricinoleic acid } \\
\mathrm{P} / \mathrm{S}=1 \\
\mathrm{~A} / \mathrm{P}=3.2\end{array}$ & \\
\hline $\begin{array}{l}\text { Concetto Spaziale } \\
\quad(62066)\end{array}$ & Pink paint & $\mathrm{Zn}$ & $\begin{array}{l}\text { Oil-based paint } \\
\text { Zinc carboxylates } \\
\text { Organic red } \\
\text { dyestuff } \\
\text { Calcium carbonate }\end{array}$ & $\begin{array}{l}\text { Antinolo Red B also known as Thioindigo Red B } \\
\text { ((2Z)-2-(3-oxo-1-benzothiophen-2-ylidene)-1- } \\
\text { benzothiophen-3-one) } \\
\text { Saturated monocarboxylic (lauric, myristic, } \\
\text { palmitic, stearic) and dicarboxylic (suberic, } \\
\text { azelaic, sebacic) acids; unsaturated (oleic) } \\
\text { acids; glycerol; special unsaturated fatty acids } \\
\text { (erucic and gondoic and their oxidation } \\
\text { products 13,14-dihydroxydocosanoic and } \\
\text { 11,12-dihydroxyeicosanoi acids) } \\
\mathrm{P} / \mathrm{S}=3.5 \\
\mathrm{~A} / \mathrm{P}=1.6\end{array}$ & \multirow[t]{3}{*}{$\begin{array}{l}\text { The pink coloration is given by an organic red } \\
\text { dyestuff }(\text { Antinolo Red } \mathrm{B}) \text { whitened with zinc } \\
\text { oxide }(\mathrm{ZnO}) \text {. Calcium carbonate }\left(\mathrm{CaCO}_{3}\right) \text { was } \\
\text { added as filler/extender. Zinc soaps were } \\
\text { detected } \\
\text { The paint is an oil-based paint containing } \\
\text { rapeseed oil }\end{array}$} \\
\hline $\begin{array}{l}\text { Concetto Spaziale } \\
(1737 / 92)\end{array}$ & Pink paint & $\begin{array}{l}\text { As for Concetto } \\
\text { Spaziale } \\
(62066)\end{array}$ & $\begin{array}{l}\text { As for Concetto } \\
\text { Spaziale } \\
(62066)\end{array}$ & $\begin{array}{l}\text { As for Concetto Spaziale }(62066) \text { but } \\
P / S=3.4 \\
A / P=1.8\end{array}$ & \\
\hline $\begin{array}{l}\text { Concetto Spaziale. } \\
\text { Fine di Dio } \\
\text { (63 FD 14) }\end{array}$ & Pink paint & $\begin{array}{l}\text { As for Concetto } \\
\text { Spaziale } \\
(62 \text { 0 66) }\end{array}$ & $\begin{array}{l}\text { As for Concetto } \\
\text { Spaziale } \\
(62066)\end{array}$ & $\begin{array}{l}\text { As for Concetto Spaziale }(62066) \text { but } \\
P / S=3.4 \\
A / P=1.7\end{array}$ & \\
\hline \multirow[t]{2}{*}{$\begin{array}{l}\text { Concetto Spaziale. } \\
\text { Fine di Dio } \\
\text { (63 FD 23) }\end{array}$} & Black paint & $\mathrm{Ca}, \mathrm{P}, \mathrm{Fe}, \mathrm{Pb}, \mathrm{Zn}$ & $\begin{array}{l}\text { Drying oil } \\
\text { Prussian blue/black } \\
\text { silicates }\end{array}$ & $\begin{array}{l}\text { Saturated monocarboxylic (lauric, myristic, } \\
\text { palmitic, stearic) and dicarboxylic (suberic, } \\
\text { azelaic, sebacic) acids; unsaturated (oleic) } \\
\text { acid; glycerol } \\
\mathrm{P} / \mathrm{S}=1.3 \\
\mathrm{~A} / \mathrm{P}=3.1\end{array}$ & $\begin{array}{l}\text { The black coloration is due to the } \\
\text { presence of pigments such as bone } \\
\text { black or ivory black }\left(\mathrm{Ca}_{3}\left(\mathrm{PO}_{4}\right)_{2}\right) \text { and } \\
\text { Prussian blue }\left(\mathrm{Fe} \mathrm{F}_{4}\left(\mathrm{Fe}(\mathrm{CN})_{3}\right)_{3}\right) \text {. The } \\
\text { presence of quartz and silicates is } \\
\text { linked to the use of sequins, which } \\
\text { were applied on the painted surface } \\
\text { using a poly-vinyl-acetate-based glue }\end{array}$ \\
\hline & $\begin{array}{l}\text { Adhesive for } \\
\text { sequins }\end{array}$ & - & $\begin{array}{l}\text { Poly-vinyl-acetate } \\
\text { (PVAc) }\end{array}$ & - & $\begin{array}{l}\text { The paint medium is a drying oil } \\
\text { (linseed oil?) }\end{array}$ \\
\hline $\begin{array}{l}\text { Concetto spaziale. } \\
\text { Fine di Dio } \\
\text { (64 FD 5) }\end{array}$ & Yellow paint & $\mathrm{K}, \mathrm{Cr}, \mathrm{Zn}$ & $\begin{array}{l}\text { Drying oil } \\
\text { Zinc carboxylates } \\
\text { Calcium carbonate }\end{array}$ & $\begin{array}{l}\text { Saturated monocarboxylic (lauric, myristic, } \\
\text { palmitic, stearic) and dicarboxylic (suberic, } \\
\text { azelaic, sebacic) acids; unsaturated (oleic) } \\
\text { acids; glycerol; special unsaturated fatty acids } \\
\text { (erucic and gondoic and their oxidation } \\
\text { products } 13,14 \text {-dihydroxydocosanoic and } \\
11,12 \text {-dihydroxyeicosanoi acids) } \\
\mathrm{P} / \mathrm{S}=1.7 \\
\mathrm{~A} / \mathrm{P}=1\end{array}$ & $\begin{array}{l}\text { The painted layers are composed of zinc yellow } \\
\left(\mathrm{ZnCrO}_{4}+\mathrm{K}_{2} \mathrm{CrO}_{4}\right) \text { and an oil-based paint } \\
\text { containing rapeseed oil probably mixed with } \\
\text { linseed oil } \\
\text { Calcium carbonate }\left(\mathrm{CaCO}_{3}\right) \text { was added as } \\
\text { filler/extender. Zinc soaps were detected }\end{array}$ \\
\hline
\end{tabular}

$\mathrm{P} / \mathrm{S}$ : palmitic to stearic acid ratio (suggesting the kind of oil); $\mathrm{A} / \mathrm{P}$ : azelaic to palmitic acid ratio (indicating the degree of oxidation/polymerization of an oil).

${ }^{\text {a }}$ Fatty acid are intended as their correspondent methyl esters, while glycerol reacted forming (trifluoromethyl)phenyl ethers. 

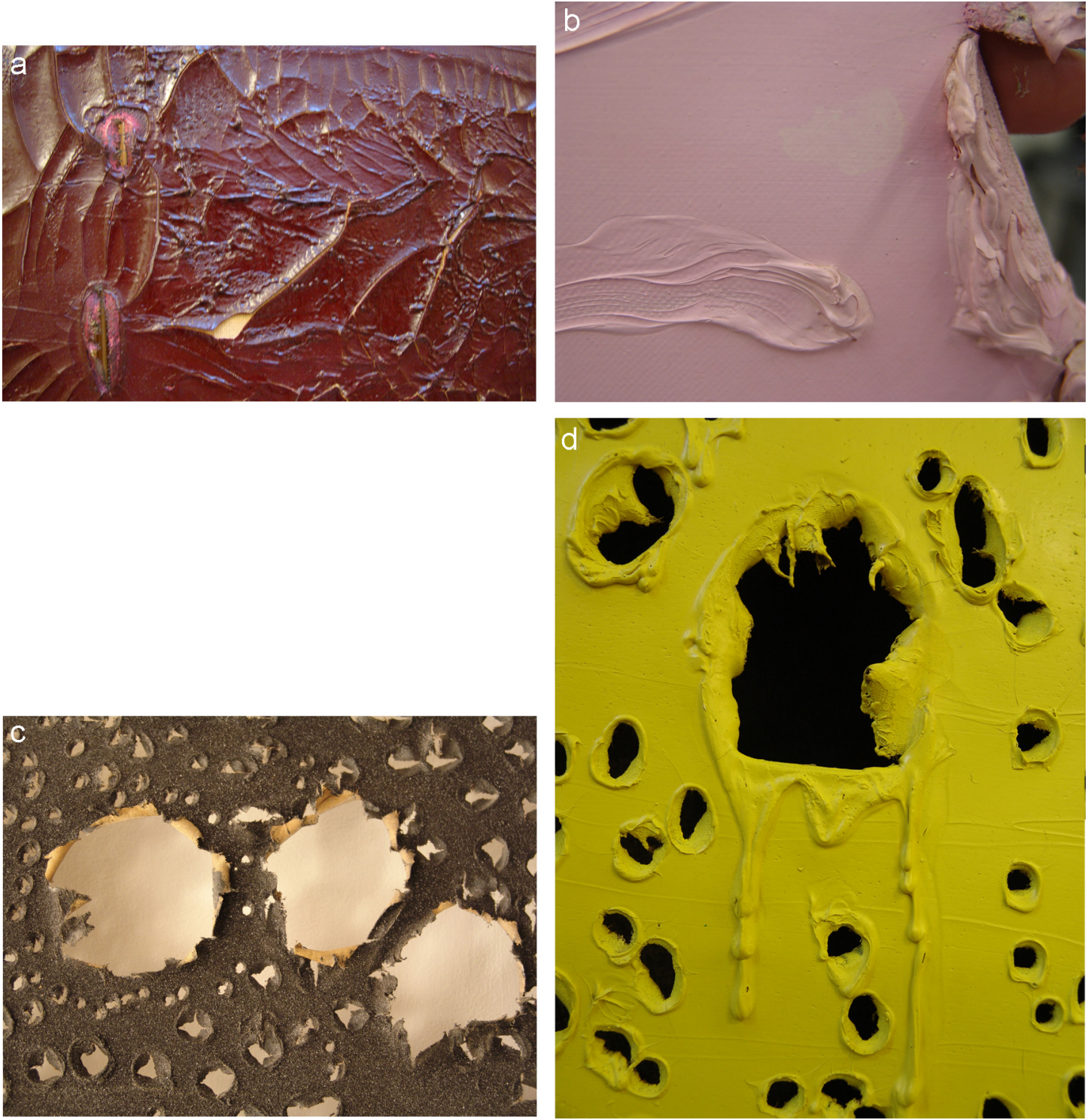

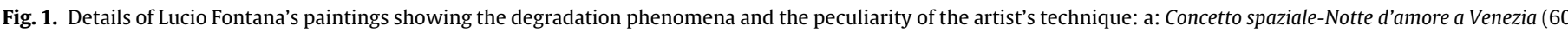

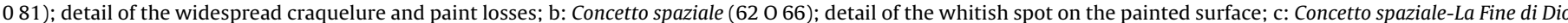
(63 FD 23); detail of the deformation of the edges of the slashes; d: Concetto spaziale-La Fine di Dio (64 FD 5); detail of the cuts and slashes on the painted canvas.

[12-14]. The coloration of the red-brown paint is attributable to the presence of alizarin, an organic red dyestuff mainly composed of 1,2-dihydroxyanthraquinone [15], while the medium was identified as an oil. In addition to the usual saturated and unsaturated fatty acids, the presence of ricinoleic acid, formally called 12-hydroxy-9-cis-octadecenoic, was detected by GC-MS analysis (Fig. 2a). This monounsaturated fatty acid is the main constituent (up to 95\%) of castor oil, which is a non-drying oil obtained from castor seeds. It is likely that the red paint in this painting contained modified linseed oil, that is linseed oil with the addition of castor oil, as suggested also by the fact that after 50 years, the painting does not appear to have dried completely. The presence of this oil binder may explain some of the signs of degradation evident in the pictorial layers (both hard fractured and sticky areas), and the wrinkles that have formed on the surface might be linked to this use of castor oil in the thick, bodied pictorial layer. Over time, the evaporation of volatile compounds (such as alcohols, aldehydes and ketones) from the oxidative cross-linking reactions occurred, leading to weight losses [16]. As the drying speed is slowed by the presence of a non-drying oil, it is possible that the evaporation rate also occurred slowly, causing the formation of more visible, deeper wrinkles [17].

Then three 'pink' Concetto spaziale (a detail of the painting labelled 62066 is depicted in Fig. 1b) were studied, since they demonstrated similarities regarding the degradation phenomena (see Table 1) and the formulation of the paints, the results are hereinafter treated together. The pink colour was found to be the result of a mixture of an organic red dyestuff (likely Antinolo Red B also known as Thioindigo Red) with zinc white ( $\mathrm{ZnO})$ as whitener. The binding media were identified as drying oils; moreover, all the FTIR-ATR spectra reported a clear, broad carboxylate absorption around $1570-1540 \mathrm{~cm}^{-1}$ (see the spectrum depicted in Fig. 3a). These peaks are possibly the result of the influence of zinc white in the drying and ageing of the oil as they could refer to the formation of metal carboxylates (soaps) with the carboxylic acids present $[12,18]$. Metal soaps can be formed after hydrolysis of the fatty acid molecules in the triglycerides of drying oils with metal-based pigments; however, the presence of added stearates as dispersion 

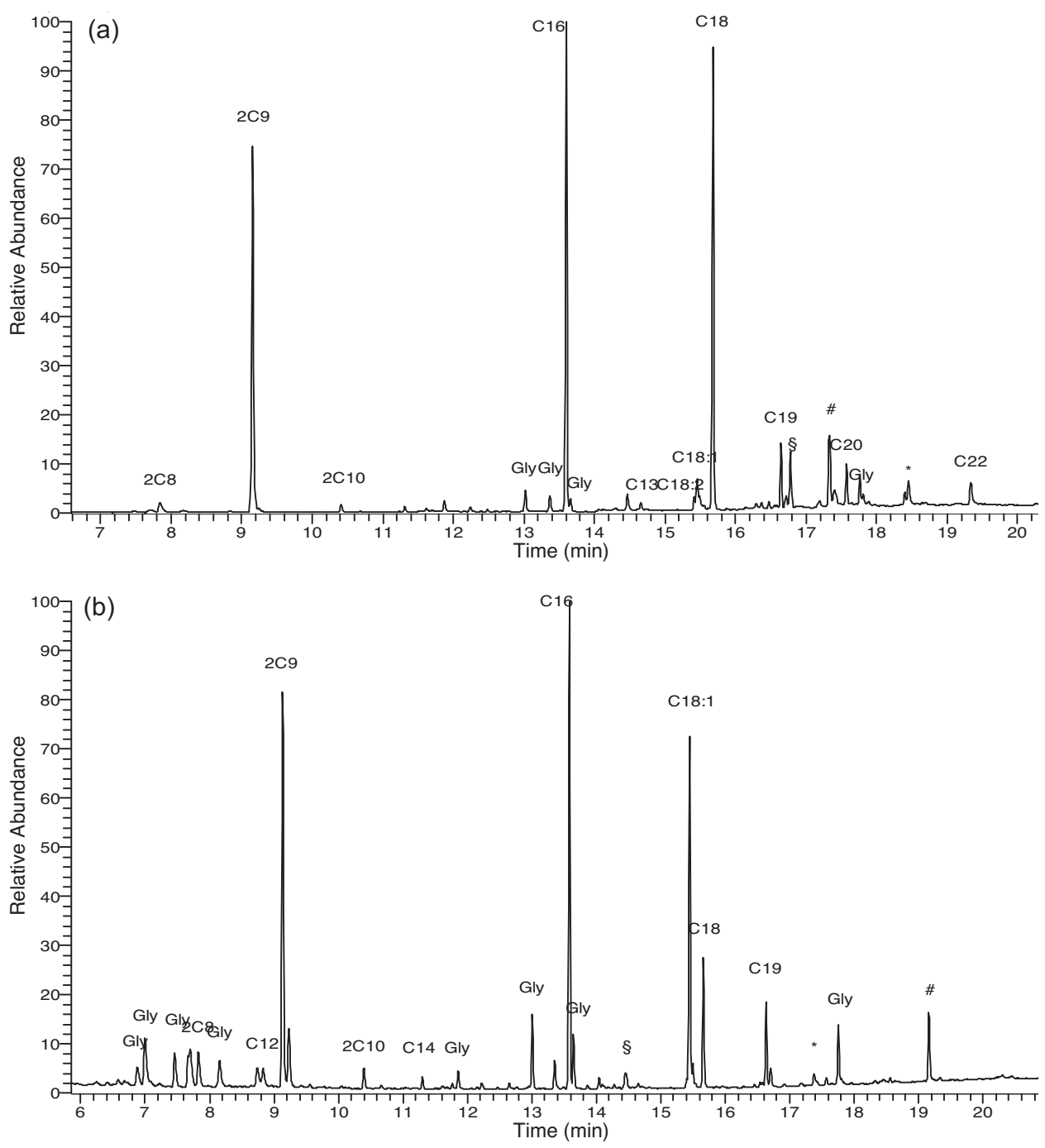

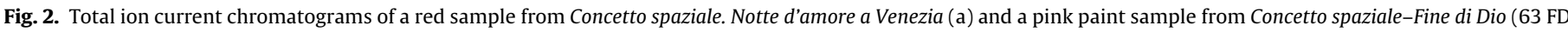

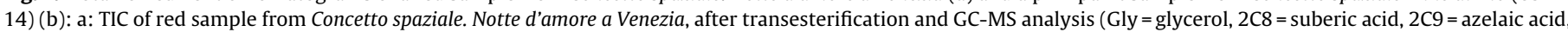

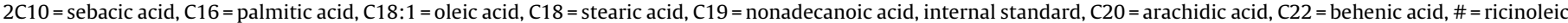

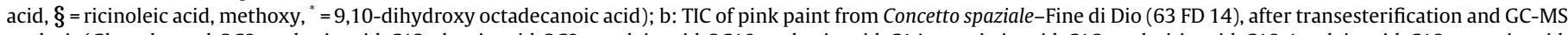

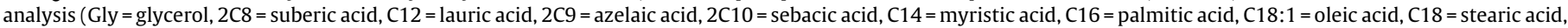
C19 = nonadecanoic acid, internal standard, ${ }^{*}=$ gondoic acid, \# = erucic acid).

agents in the paint formulation $[19,20]$ cannot be excluded. A minor addition of calcium carbonate as a filler or extender is suggested by carbonatic absorption peaks at 1413 and $873 \mathrm{~cm}^{-1}$. Amongst the characteristic drying oil compounds, two uncommon fatty acids were detected by GC-MS analysis (Fig. 2b): erucic (13-docosenoic) and gondoic (11-eicosenoic) acids and their oxidation products (13,14-dihydroxydocosanoic acid and 11,12-dihydroxyeicosanoic acid respectively). These unsaturated fatty acids are considered to be bio-markers as they are present only in oils obtained from the seeds of Brassicaceae, such as rapeseed oil [21]. Moreover, the P/S ratios for the pink works are around 3.6 and may refer to the use of rapeseed oil (whose P/S is around 3.5-3.8) as binding media. This is a semi-drying oil which was introduced in the 20th century according to modern artists' handbooks [4,5]. The high content of oleic acid and the consequentially high degree of unsaturation is most likely to be a consequence of the presence of a slow-drying oil, but this phenomena could also be explained in another way - in fact, the significant amounts of oleic acid may be linked to the presence of zinc oxide, which have also been noted in other artworks. It would thus appear that in an oil-based medium, zinc oxide forms a packed structure which is able to trap oleic acid in the pictorial layer: this effect can also occur years after the oxidation process ends [22-24]. The unusual degradation phenomena observed in all of these paintings might be the result of the presence of a slow-drying oil (rapeseed oil) containing a large amount of unsaturated acids (oleic, erucic and gondoic were detected after almost 50 years) whose triglycerides reacted with zinc white from the painted layers to form metal soaps. As FTIR analyses suggest, metal soaps are present in the form of zinc carboxylates, and hence it is probable that zinc soaps are present as formed and/or added soaps (as dispersion agents) and that they migrated and conglomerated on the surface, forming the light yellow spots.

Although it did not show any evident degradation phenomena on the surface (Fig. 1d), similar results were found for the artwork named Concetto spaziale. Fine di Dio, (64 FD 5). The yellow coloration is due to the use of zinc yellow $\left(\mathrm{ZnCrO} 4+\mathrm{K}_{2} \mathrm{CrO}_{4}\right)$ (see XRF reported in Fig. 4), while the medium is an oil. GC-MS results are comparable with the pink series: besides the presence of common fatty acids, the yellow paint exhibits high amounts of unsaturated oleic, gondoic and erucic acids. The presence of rapeseed oil is also suggested in this case, although the $\mathrm{P} / \mathrm{S}$ ratio is 

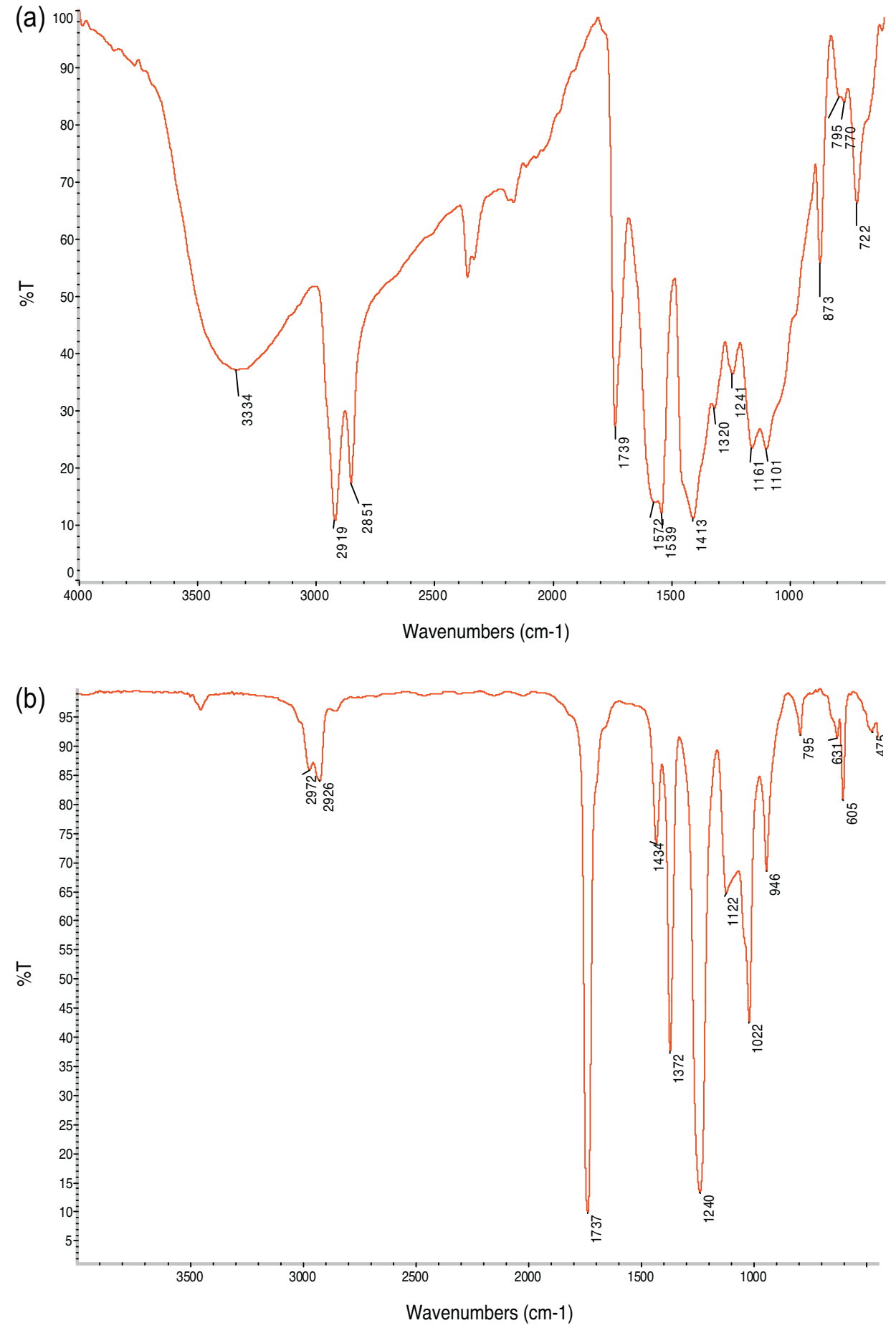

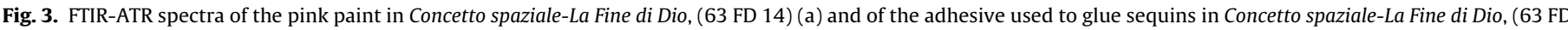

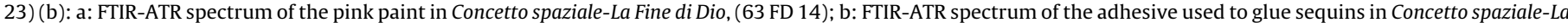
Fine di Dio, (63 FD 23).

1,7- this value suggests the mixture with other oil media (such as the traditional linseed oil). As observed in the pink Olii, the abundant oleic acid content might be related to the action of zinc pigments and the broad FTIR peak at $1574 \mathrm{~cm}^{-1}$ can be explained by the presence of zinc soaps, formed and/or added in the paint formulation.

The last analysed painting is a black Concetto spaziale-Fine di Dio (63 FD 23) (Fig. 1c), whose coloration is due to the presence of pigments such as bone black or ivory black $\left(\mathrm{Ca}_{3}\left(\mathrm{PO}_{4}\right)_{2}\right)$ and Prussian blue $\left(\mathrm{Fe}_{4}\left(\mathrm{Fe}\left(\mathrm{CN}_{6}\right)_{3}\right)\right)$. From samples taken from the pictorial layer (including areas in which the sequins were present), it was ascertained that it was a oil-based paint. The high degree of unsaturation associated with the high content of oleic acid suggests that the paint, even 50 years after its application to the canvas, is still immature or that a non-drying oil was added to the paint. The $\mathrm{P} / \mathrm{S}$ ratio is 1.3 , value which is conventionally referred to linseed oil [25]; nevertheless, the use of this traditional binder is rather improbable, due to the different behavior shown by the pictorial layer under examination. It is likely that other lipidic binders, exhibiting similar $\mathrm{P} / \mathrm{S}$ ratio, were employed $[4,5,11,21]$. In this sample, the 


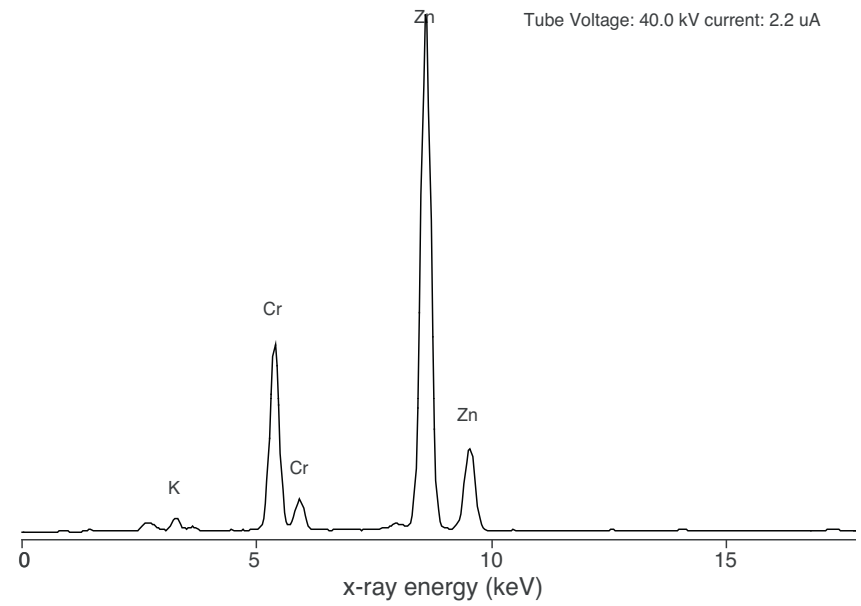

Fig. 4. XRF spectrum of a yellow paint sample from Concetto spaziale-La Fine di Dio (64 FD 5).

sequins appeared not only to be embedded in the pictorial film, but in some places were also embedded in a superficial layer of polyvinyl acetate (PVA)-based adhesive (most likely to be Vinavil ${ }^{\circledR}$, produced by the Italian company Montecatini) (Fig. 3b). This glue could have played a role in the creation of tensions and the deformation of the pictorial layers, however there is also the possibility that this alteration could be caused by the extreme thinness of the pictorial film.

\section{Conclusions}

The results obtained by this study have provided us with important information regarding the works of the Olii series created by Lucio Fontana between 1960 and 1964. During the same period, the artist experimented with several different and innovative pictorial binders, but still tended towards more traditional binding materials. Fontana himself was known to be an experimental artist and he used to mix house paints with manufactured oil paints [7-9]. Nevertheless, as we have proven, Fontana used oil paints containing different lipidic binders: a non-drying oil such as castor oil, a semi-drying oil such as rapeseed oil and the traditional drying binder, linseed oil. It is not clear if Fontana wished to experiment with different kinds of oils in order to achieve different effects or if he simply used readymade paints without knowing their composition, however, the materials and the techniques that he used are now proven to be closely linked to the conservation problems exhibited by the pictorial layers and observed during conservation treatments. Furthermore, these analyses gave unexpected, but useful results which not only provided us with new insight into the nature of the constituent materials, but also facilitated the identification of suitable conservation methods.

From an analytical point of view, this study has reinforced previously stated conclusions that maintain that modern and contemporary artists used and still use varying forms of this traditional medium - which are often generically labelled as 'oils' - without any specific regard to their binding properties. The uninformed use of these oils demands that each case study be analysed separately in order to develop suitable treatment methods for each and every work and avoid detrimental generalisations.

\section{Acknowledgements}

This research project was made possible thanks to the collaboration of the Fondazione Lucio Fontana in Milan and is the result of a collaboration between the Ca' Foscari University of Venice and the Netherlands Cultural Heritage Agency/RCE (Rijksdienst voor Cultureel Erfgoed, formerly ICN-Instituut Collectie Nederland) and is part of the wider 20th Century oil paints Project carried out by RCE in cooperation with the Courtauld Institute of Art (CIA), the Getty Conservation Institute $(\mathrm{GCI})$ and the Tate. Special thanks go to Dr. Luc Megens and Dr. Suzan De Groot of RCE for their assistance in performing XRF and FTIR-ATR analyses.

This study was financially supported by the 2008-2010 PRIN Project "Behaviour of polymeric pictorial films and methods for the conservation".

\section{References}

[1] T.J.S. Learner, Analysis of modern paints, The Getty Conservation Institute, Los Angeles, 2004.

[2] M. Pugliese, I materiali sintetici nell'arte contemporanea, Kermes 30 (1997) 21-30.

[3] O. Chiantore, A. Rava, Conservare l'arte contemporanea: problemi, metodi, materiali, ricerche, Mondadori Electa, Milano, 2005

[4] R. Mayer, The artist's handbook of materials and techniques. Revisited Edition, Viking, New York, 1991.

[5] M. Doerner, The materials of artists and their use in painting, Harvest, San Diego/New York/London, 1984.

[6] B. Ferriani, R. Ploeger, T. Poli et alii, Lucio Fontana. Between tradition and innovation, in: Art d'aujourd'hui. Patrimoine de demain, Conservation et restauration des œuvres contemporaines, Paris, 2009.

[7] P. Gottschaller, Lucio Fontana: The Artist's Materials, The Getty Conservation Institute, 2012.

[8] P. Gottschaller, N. Khandekar, L.F. Lee, D. Kirby, The evolution of Lucio Fontana's painting materials, Stud. Conserv. 57 (2012) 76-91.

[9] O. Chiantore, R. Ploeger, T. Poli, B. Ferriani, Materials and techniques in the pictorial oeuvre of Lucio Fontana, Stud. Conserv. 57 (2012) 92-105.

[10] K.R. Sutherland, Derivatisation using m-(trifluoromthyl)phenyltrimethylammonium hydroxide of organic materials in artworks for analysis by gas chromatography-mass spectrometry: unusual reaction products with alcohols, J. Chromatogr. A 1149 (2007) 30-37.

[11] F.C. Izzo, 20th century artists' oil paints: a chemical-physical survey (PhD thesis), University Ca' Foscari, Venice, 2011.

[12] j. van der Weerd, A. van Loon, J.J. Boon, FTIR studies of the effects of pigments on the ageing of oil, Stud. Conserv. 50 (2005) 3-22.

[13] R. Arbizzani, U. Casellato, E. Fiorin, L. Nodari, U. Russo, P.A. Vigato, Decay markers for the preventative conservation and maintenance of paintings, J. Cult. Herit. 5 (2) (2004) 167-182.

[14] M. Favaro, S. Bianchin, P.A. Vigato, M. Vervat, The palette of the Macchia Italian artist Giovanni Fattori in the second half of the XIXth century, J. Cult. Herit. 11 (3) (2010) 265-278.

[15] E. Kampasakali, E.A. Varella, The Russian avant-garde painting palette: Documentary and physicochemical codification of organic colorants, J. Cult. Herit. 9 (1) (2008) 77-88

[16] J.D.J. van den Berg, K.J. van den Berg, J.J. Boon, Chemical changes in curing and ageing oil paints, ICOM Committee for conservation preprints 1 (1999) $248-253$.

[17] D. Erhardt, S.C. Tumosa, M.F. Mecklenburg, Long-term chemical and physical processes in oil paint films, Stud. Conserv. 50 (2005) 143-150.

[18] L. Robinet, M.C. Corbeil, The characterization of metal soap, Stud. Conserv. 48 (2003) 23-40.

[19] C.S. Tumosa, A brief history of aluminum stearate as a component of paint, Waac Newslett. 23 (2001) 10-11.

[20] A. Burnstock, K.J. van der Berg, S. de Groot et alii, An investigation of watersensitive oil paints in the 20th century paintings, in: T.J.S. Learner, P. Smithen, J. Krueger et alii (Eds.), Modern Paints Uncovered, The Getty Conservation Institute, Los Angeles, 2007, pp. 177-188.

[21] M.P. Colombini, F. Modugno, Organic mass spectrometry in art and archaeology, Wiley \& Sons, New York, 2009.

[22] D. Rogala, S. Lake, C. Maines, M. Mecklenburg, Condition problems related to zinc oxide underlayers: examination of selected abstract expressionist paintings from the collection of the Hirshhorn Museum and sculpture garden, Smithsonian Institution, J. Am. Inst. Conserv. 46 (2010) 96-113.

[23] G. Osmond, Zinc white: a review of zinc oxide pigment properties and implications for stability in oil-based paintings, AICCM Bull. 32 (2011) 20-29.

[24] G. Osmond, J.J. Boon, L. Puskar, J. Drennan, Metal stearate distributions in modern artists' oil paints: surface and cross-sectional investigation of reference paint films using conventional and synchrotron infrared microspectroscopy, Appl. Spectrosc. 66 (2012) 1136-1144.

[25] J.S. Mills, The gas chromatographic examination of paint media. Part I. Fatty acid composition and identification of dried oil film, Stud. Conserv. 11 (1966) 92-108. 